\title{
COMUNA 7 DE BARRANCABERMEJA: UNA PROPUESTA PARTICIPATIVA DE ORDENACIÓN TERRITORIAL EN BARRIOS DE ORIGEN INFORMAL ${ }^{1}$.
}

\author{
Luis Molina López ${ }^{2}$ \\ Grupo de Estudios Urbano-Regionales del Magdalena Medio. \\ Instituto Universitario de la Paz UNIPAZ.
}

Remisión artículo: 1-11-2007

Palabras Clave: Ordenación territorial, participación ciudadana, informalidad urbana.

Resumen: La Comuna 7 de la ciudad de Barrancabermeja, está construyendo desde hace más de 10 años, una propuesta participativa de ordenación territorial con perspectiva regional, que permita disminuir los problemas de desequilibrio espacial, de segregación social y de violencia que afectan, no solo a la Comuna sino a la ciudad en general. Dentro de este marco general de análisis, el artículo busca (dentro de un marco de cualificación de la realidad social), visibilizar un proceso comunitario que ha retomado las herramientas de planeamiento urbano de la Ley 388 de 1997, para construir acciones colectivas de resistencia civil frente a los grupos armados ilegales, al tiempo que avanza en procesos de participación efectiva de sus pobladores, en la toma real de las decisiones que atañen a su propio desarrollo socio-territorial.

\section{Introducción.}

El proceso social adelantado en la Comuna 7 de Barrancabermeja, es una experiencia significativa en materia de participación real de las comunidades más pobres en la toma de decisiones que permitan la construcción de un modelo de desarrollo urbano incluyente, ya que su contexto socio-territorial, se desenvuelve en medio de circunstancias completamente adversas y asociadas a la ausencia de implementación de políticas públicas ${ }^{3}$ que permitan disminuir los problemas de desequilibrio espacial, de exclusión social y de violencia que históricamente han caracterizado a dicha ciudad y a los sectores orientales de la misma.

El artículo busca describir, en medio de un marco metodológico de cuantificación y cualificación de la realidad social y más específicamente desde la ordenación participativa del territorio, el proceso adelantado en más de "una década de persistente y sistemática actividad, en torno a la integración de las diferentes formas de la organización social y comunitaria" ${ }^{4}$, que como ya se explicará, se ha convertido en herramienta fundamental para la construcción de un modelo urbano de desarrollo social, económico y espacialmente equilibrado.

En este contexto, el artículo contiene 4 apartados: el primero, aborda el contexto empírico y la metodología de análisis desarrollada en el ejercicio comunal; el segundo apartado, evidencia el proceso histórico del proyecto Ciudadela Educativa y Desarrollo Integral de la Comuna 7, además presenta los aspectos centrales de partida en cuanto a las problemáticas más relevantes y desarrolla una síntesis de la propuesta de ordenación territorial comunal; el tercero, aborda los retos y perspectivas futuras del proyecto $\mathrm{y}$, el último, presenta las

\footnotetext{
${ }^{1}$ Articulo presentado en el Seminario Internacional Procesos Urbanos Informales. Realizado por la Facultad de Artes de la Universidad Nacional de Colombia, en la ciudad de Bogotá los días 31 de octubre, 1 y 2 de Noviembre de 2007. ${ }^{2}$ Persona de contacto: Luis Molina López, correo electrónico: luis.molina@unipaz.edu.co, pdrmolina@yahoo.com

${ }^{3}$ Según Vargas (2001, pág. 57), las políticas públicas se entienden como "el conjunto de iniciativas, decisiones y acciones de un régimen político frente a cuestiones socialmente problemáticas, que pretenden o que buscan resolver esa situación o tornarla manejable".

${ }^{4}$ Documento de Formulación Plan de Desarrollo Integral de la Comuna 7 de Barrancabermeja (2004).
} 
reflexiones finales centrándose en los aspectos de ordenación territorial, así como en los avances y retos del proyecto comunitario.

En síntesis, el artículo visibiliza un proceso comunitario de ordenación territorial con perspectiva regional, adelantado en barrios de origen informal, en donde las acciones colectivas de sus pobladores han logrado avanzar en formas efectivas de resistencia civil contra los grupos armados ilegales, al tiempo que han construido un proyecto incluyente de desarrollo que le ha permitido acceder a recursos de cooperación internacional, como la Unión Europea, en el marco general de la ejecución del Laboratorio de Paz en el Magdalena Medio.

\section{Contexto empírico y metodología de análisis}

Desde el punto de vista metodológico, el ejercicio adelantado en la Comuna 7 de Barrancabermeja, durante la última década, aplica los fundamentos de participación democrática de las organizaciones sociales contemplados en la Ley 134 de 1994, y retoma los objetivos y principios establecidos en la Ley 388 de 1997, acerca de la construcción colectiva de un modelo de desarrollo urbano, que permita avanzar hacia un planeamiento de desarrollo local con perspectiva regional. Durante estos últimos 10 años el proceso comunal ha efectuado una serie de ejercicios participativos, los cuales han permitido obtener información actualizada de cada uno de los aspectos físico-espaciales más relevantes, dicha información es el resultado del trabajo de campo desarrollado por las mismas comunidades, con la colaboración de profesionales, así como de entidades públicas y privadas acompañantes del proceso.

En este sentido, los ejercicios realizados y de mayor relevancia para el proceso, son en su orden: la Formulación del Plan Parcial, la Formulación del Proyecto Educativo Comunal PEC, la Formulación del Plan de Desarrollo de la Comuna 7, y la Revisión y Ajuste al Plan Parcial de Ordenamiento Territorial Comunal. Ahora bien, tanto la formulación como la revisión del plan parcial de la Comuna 7, llevados a cabo en los años 2001 y 2007 respectivamente, se centraron en tres aspectos centrales: 1) en la realización de talleres de formación ciudadana sobre elementos conceptuales y metodológicos de la planificación del desarrollo local; 2) en el trabajo con cartografía social y, 3) en la identificación de Fortalezas, Oportunidades, Debilidades y Amenazas, con miras a definir las problemáticas del territorio comunal. Adicionalmente se identificaron los proyectos necesarios que podrían dar respuesta a dichas problemáticas, y asimismo se plantearon estrategias de seguimiento y evaluación participativas, de forma tal que permitieran adelantar las acciones necesarias para su sostenimiento en el tiempo.

Se debe resaltar que un avance significativo para la recolección de información espacial, en la formulación del plan parcial como en su revisión y ajuste, se relaciona con el trabajo de campo llevado a cabo con los líderes comunitarios, allí se recogió información que permitió comparar los datos obtenidos en el 2001 con la información espacial existente en el 2007, en aspectos tales como: el estado de las vías, de las viviendas, de los equipamientos colectivos, de los usos del suelo, de los servicios públicos domiciliarios, de las zonas susceptibles de amenaza, entre otras; información que permitió a las comunidades ver el grado de avance frente a las propuestas planteadas en el primer ejercicio realizado en el 2001. Finalmente, se debe recalcar que los ejercicios de cartografía social, permitieron develar y reconstruir las relaciones socioespaciales presentes entre los pobladores de los diferentes barrios que componen la comuna, ya que ésta, se convirtió no solo en una forma de comunicación no verbal, sino que acrecentó los niveles de conocimiento de las comunidades sobre su propio territorio, así como de las acciones a desarrollar en él. 


\section{El proyecto ciudadela educativa y desarrollo integral de la Comuna 7 de Barrancabermeja}

En el presente ítem se hará especial énfasis en el proceso histórico del proyecto ciudadela educativa, en sus aspectos centrales de partida (educación, relaciones con el acceso a la tierra, segregación espacial y políticas de planeación) y en la propuesta específica de ordenación territorial.

\subsection{El proceso histórico del proyecto ${ }^{5}$.}

La estructura socio-espacial urbana actual de Barrancabermeja, evidencia marcados desequilibrios funcionales en la disposición de sus elementos articuladores, ya que estos se agrupan principalmente en las comunas 1 y 2 , siendo estas las que concentran tan solo el $24,8 \%$ de la población urbana, dejando desprovistas las otras cinco comunas, con mayor porcentaje de población y donde se encuentran los mayores índices de necesidades básicas insatisfechas. Históricamente la ciudad se ha caracterizado por su excluyente organización espacial, muestra evidente de esta situación, se aprecia en sus orígenes con la configuración impuesta a su llegada, por la Tropical Oil Company, la cual “...instaló campamentos para trabajadores colombianos, separados por mallas y celadores de los campamentos en donde se hospedaba el personal norteamericano..." (Archila et al, 2006:262). La anterior situación reafirma el postulado acerca de los fuertes procesos de segregación espacial negativa ${ }^{6}$ que se han dado en Barrancabermeja desde sus inicios, y que al día de hoy se ven claramente expresados en una configuración espacial que da cuenta de una ciudad fragmentada y excluyente entre oriente, la ciudad de origen informal, y occidente, la ciudad de origen formal (ver figura 1).

Debido a los históricos desequilibrios espaciales y a las actuales circunstancias de exclusión y fragmentación territorial negativa de la ciudad, surge una propuesta colectiva organizada denominada Proyecto Ciudadela Educativa y Desarrollo Integral de la Comuna 7 de Barrancabermeja, el cual tiene sus inicios a mediados de la década de los años 90 como respuesta a las falsas promesas y engaños, que históricamente los políticos de turno han efectuado sobre las comunidades más pobres de la ciudad. Ante aquella situación, varios líderes de la Comuna 7 de Barrancabermeja, denominados equipo gestor ${ }^{7}$, emprenden un proceso de re-estructuración de las juntas de acción comunal e inician una serie de reflexiones, en donde resalta el papel de la educación, como el punto de partida para planificar su propio desarrollo y construir un proyecto de vida incluyente, que les permita avanzar hacia la consecución de un mejor bienestar económico, político, social y ambiental.

En 1997 con el arribo de la inversión privada a la comuna, especialmente con el montaje de una planta generadora de energía eléctrica ${ }^{8}$, se presenta una situación compleja, ya que para su montaje se requería de expertos norteamericanos de la Westing House, para lo cual se

\footnotetext{
${ }^{5}$ Elaborado con base en la entrevista realizada a Andrés Aldana Berrio, uno de los ocho líderes comunitarios del equipo gestor del proyecto Ciudadela Educativa y Desarrollo Integral de la Comuna 7 de Barrancabermeja.

${ }^{6}$ Según Sabatini (2003:13) Los efectos de la segregación "pueden ser tanto positivos como negativos. [...], la formación de enclaves étnicos es positiva tanto para la preservación de las culturas de grupos minoritarios como para el enriquecimiento de las ciudades, que se tornan más cosmopolitas".

${ }^{7}$ El Equipo gestor, lo conforman 8 líderes comunitarios que le han hecho frente, de forma pacífica, a los diferentes grupos armados ilegales presentes en la Comuna 7 y se han dado a la tarea de construir un proyecto comunal que permita disminuir los desequilibrios socioeconómicos y espaciales que afronta una de las comunas con mayores niveles de pobreza, violencia y desigualdades sociales en Barrancabermeja.

${ }^{8}$ Actualmente la planta recibe el nombre de MERILECTRICA y se ha convertido en uno de los acompañantes del proceso, especialmente con el trabajo social en la organización de jóvenes alrededor de un proyecto de producción de abono orgánico.
} 
hacía necesario construir Bunkers militares, para garantizar su protección, en inmediaciones de los predios que en esos momentos eran propiedad del Ministerio de Defensa. Dicha decisión se toma por el innegable control militar y territorial que ostentaba la guerrilla del Ejército de Liberación Nacional ELN en prácticamente todo el oriente de la ciudad, en los mal llamados sectores nororientales ${ }^{9}$.

\section{Figura 1 Fragmentación urbana y segregación espacial en Barrancabermeja}

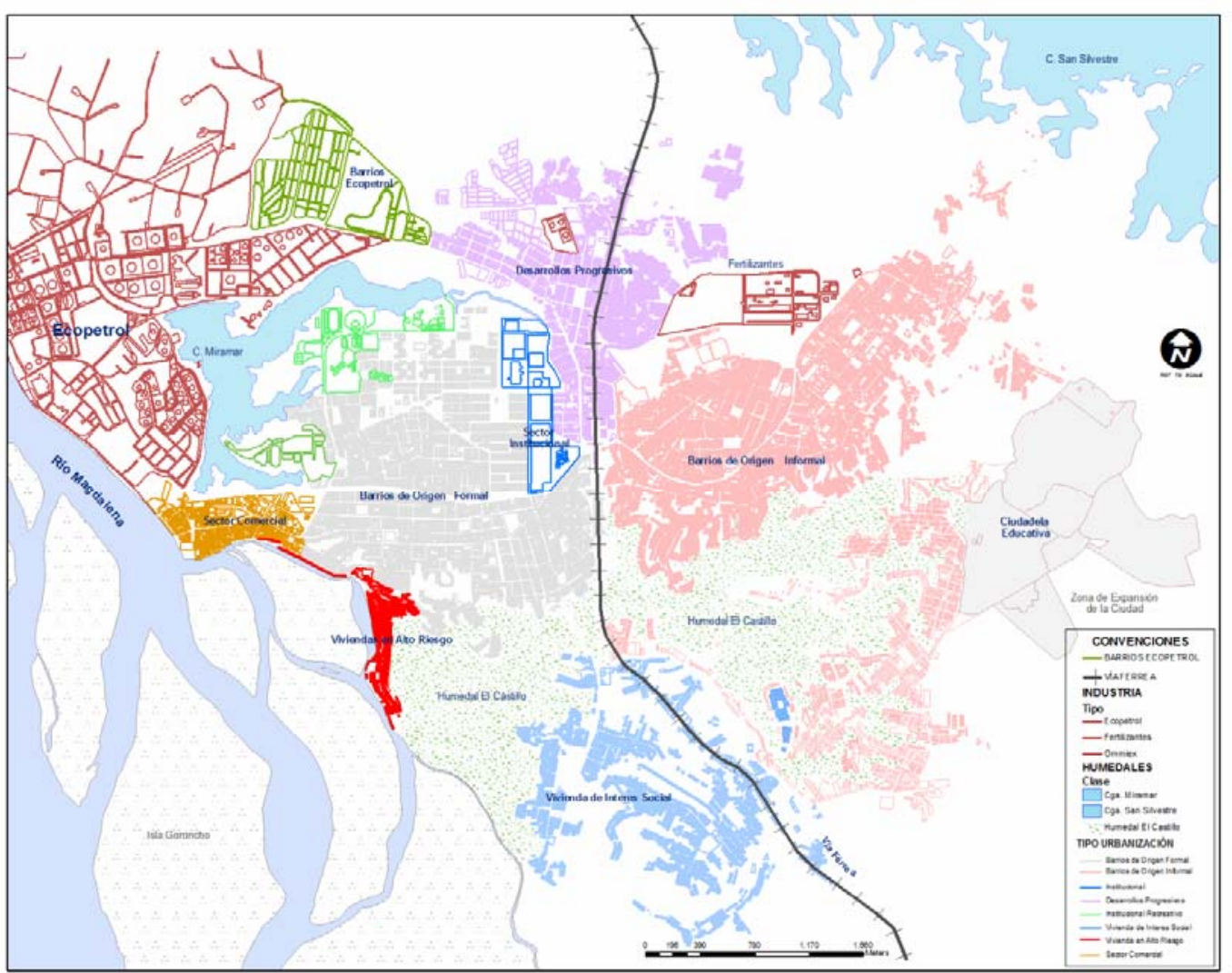

Fuente: Elaboración propia

Frente a esta situación, las comunidades a través de sus líderes reaccionan y crean una dinámica de diálogo, concertación y negociación, que propicia la creación de una comisión de garantes conformada por la Corporación Desarrollo y Paz del Magdalena Medio CDPMM, la Corporación Regional para la Defensa de los Derechos Humanos CREDHOS, la Defensoría Regional del Pueblo, la Unión Sindical Obrera USO, la Diócesis de Barrancabermeja y los líderes comunitarios. De esta comisión surge la propuesta de invertir los recursos destinados a la seguridad de los extranjeros (y con los cuales se levantarían los Bunkers), en la construcción

\footnotetext{
${ }^{9}$ Barrancabermeja tuvo durante varias décadas el control militar, de los sectores orientales de la ciudad, por parte de las guerrillas del Ejército de Liberación Nacional (ELN) y las Fuerzas Armadas Revolucionarias de Colombia (FARC), pero a partir de 1998 con la arremetida paramilitar en la región del Magdalena Medio, el control del oriente de la ciudad pasa a manos de los paramilitares.
} 
de un colegio de Bachillerato ${ }^{10}$, al tiempo que la comunidad se comprometía a colaborar en la construcción de la planta de energía eléctrica.

A partir de la negociación con el Ministerio de Defensa, se logra que los predios pasen a la Alcaldía Municipal con destinación específica para desarrollar el proyecto Ciudadela Educativa. En el año 2000 con la formulación del Plan de Ordenamiento Territorial POT de Barrancabermeja (exigencia de la Ley 388 de 1997), la comunidad organizada alrededor del equipo gestor presenta la propuesta de formular un Plan Parcial para la Comuna 7, el cual finalmente queda incluido dentro de las propuestas del POT de la ciudad; en el 2001, antes de aprobarse el Plan de Ordenamiento de Barrancabermeja, las comunidades buscan apoyo de entidades públicas y privadas ${ }^{11}$ para financiar la formulación participativa, más que de un Plan Parcial, de un proyecto colectivo de desarrollo económico, social, político y territorial, que se ha convertido en el instrumento de negociación ante los diferentes gobiernos municipales, así como de gestión de recursos del orden nacional e internacional, recibiendo especialmente apoyo de la Unión Europea, a través del Laboratorio de Paz en el Magdalena Medio.

Actualmente el proyecto se encuentra en proceso de revisión y ajuste de su Plan Parcial, en este ejercicio se ha logrado develar, que el mayor enemigo del proceso no han sido los mismos grupos armados ilegales (guerrillas y paramilitares que durante años disputaron el control militar de la ciudad), sino la falta de voluntad política de las diferentes administraciones municipales, las cuales no han dado muestras claras de avanzar en la implementación de políticas públicas y estrategias que permitan disminuir los desequilibrios socio-espaciales y la segregación negativa de amplios sectores localizados especialmente en la periferia urbana.

\subsection{Los aspectos centrales de partida.}

Antes de abordar las políticas y estrategias más relevantes de la propuesta construida con las comunidades, expresada principalmente en su Plan Parcial y en su Proyecto Educativo Comunal PEC, se realizará una breve presentación de tres aspectos centrales de partida que permitieron evidenciar cuantitativa y cualitativamente las distintas problemáticas acontecidas en la Comuna y que a su vez dieron origen a la movilización colectiva.

Al respecto es pertinente señalar que los pobladores de la Comuna $7^{12}$ de Barrancabermeja no solo poseen problemáticas asociadas a los bajos niveles socioeconómicos, sino que a su vez son estigmatizados por los efectos de la violencia acontecida en la región, producto de los enfrentamientos entre paramilitares, guerrillas y fuerzas armadas del Estado. Conviene sin embargo, advertir que la ausencia de planeación y de políticas públicas que permitan la inclusión social y la disminución de las inequidades espaciales representadas en el acceso progresivo y adecuado a servicios sociales básicos, es tal vez uno de los factores que ha ocasionado el aumento de la marginalidad de la periferia urbana, especialmente en los sectores orientales de la ciudad.

El tema de educativo. Con respecto a la educación, una de las problemáticas que dio origen a la movilización colectiva, se relaciona con la desarticulación de los proyectos educativos

\footnotetext{
${ }^{10}$ Hasta el año 2007, la Comuna 7 de Barrancabermeja no contaba con un colegio de educación media vocacional, trayendo consigo una alta tasa de deserción escolar, debido, entre otras circunstancias, a los altos costos en desplazamiento que tienen que asumir las familias de una comuna con bajos niveles socioeconómicos y altos índices de desempleo.

${ }_{11}$ Entre las entidades financiadoras de la formulación del plan parcial se encontraban: Ecopetrol, Interconexión eléctrica S.A (ISA), La Alcaldía de Barrancabermeja, la Corporación Desarrollo y Paz del Magdalena Medio (como administrador de los recursos) y el equipo gestor.

${ }^{12}$ Se debe resaltar que las comunas 5, 6 y 7 de Barrancabermeja componen el oriente de la ciudad y presentan en términos generales problemáticas similares.
} 
institucionales PEI con las necesidades de los pobladores de las comunas 5, 6 y $7^{13}$. De igual forma se aprecia que en la Comuna 7 , el $59 \%$ de la población en edad escolar ingresa a la educación básica primaria, de este porcentaje solo el 33\% continua sus estudios de secundaria, trayendo como consecuencia altos niveles de deserción escolar, desempleo juvenil, embarazo adolescente, violencia intrafamiliar y delincuencia, asociada especialmente con el ingreso de los jóvenes a grupos al margen de la Ley, y conexos con el hurto de gasolina en las redes de poliductos que pasan contiguas a la comuna.

Junto a la problemática educativa se destaca que la ciudad mantiene una fuerte concentración en sus establecimientos educativos, muestra de ello es la existencia de solo dos colegios de bachillerato en las tres comunas (comunas 5, 6 y $7^{14}$ ) con mayores índices de población en edad escolar. En este contexto se observa que los desequilibrios urbanos en equipamientos educativos incrementan la segregación socio-espacial, ya que "...conforme aumenta la segmentación entre establecimientos educativos, aumenta la probabilidad de que los miembros de un estrato social sólo se encuentren en una relación cara a cara con miembros de otros estratos sociales en el mercado de trabajo, donde las relaciones están enmarcadas en patrones jerárquicos" (Katsman, citado por Arriaga y Rodríguez, 2003, pág. 56).

Las relaciones con la tierra y el estado de la vivienda. El proceso de urbanización de las comunas orientales y de las zonas periféricas de la ciudad, se ha caracterizado por la recuperación de tierras ${ }^{15}$, como consecuencia de los desplazamientos masivos causados por la violencia regional, o promovidos por reconocidos actores políticos o por grupos armados ilegales. La reclamación de derechos seguros sobre la tierra, que permita alguna capitalización económica para las familias más pobres, ha sido una de las banderas del proceso de urbanización informal en Barrancabermeja. Según Deininger (2003 pág. xvii), "unos derechos de tierras seguros y bien definidos son clave para la propiedad legítima de los bienes, el desarrollo productivo y el funcionamiento del mercado de factores, de los hogares" no solo a nivel rural sino también urbano.

Uno de los aspectos más representativos en la configuración espacial de la comuna, luego de la urbanización informal, se evidencia en el estado físico de sus viviendas, ya que una vez adquirida la tierra mediante un proceso colectivo y autogestionario, se inicia la apropiación y adecuación del entorno inmediato para la protección de los núcleos familiares y para el acceso a infraestructura social mínima. Ahora bien, con respecto al estado de la vivienda, el ejercicio arrojó que en el periodo comprendido entre los años 2001 al 2007, la comuna aumentó en 301 nuevos predios (la mayoría de ellos producto de procesos de recuperación de tierras), de igual forma la cantidad de predios dedicados al uso exclusivo de vivienda pasó de 4.940 a 5.291 (ver tabla 1). La anterior situación se torna preocupante una vez se analizan con mayor detalle los datos, puesto que se encontró que las viviendas consolidadas ${ }^{16}$ disminuyeron en 1.927 unidades, casi la misma proporción en que aumentaron las de tipo semiconsolidado, esta

\footnotetext{
${ }^{13}$ En este sentido, se presentaban situaciones en donde una institución educativa contemplaba el énfasis en computación y sistemas, y dentro de su dotación no existía una sala equipada con computadores para su enseñanza, al igual que dentro de la planta docente no existía profesores con el respectivo perfil.

${ }^{14}$ En este punto se debe aclarar que la Comuna 7 solo hasta diciembre del año 2007 terminó la construcción de un colegio de media vocacional, con recursos de la Unión Europea, Ecopetrol y la Alcaldía Municipal.

${ }^{15}$ La conformación de los barrios de la Comuna 7 se ha dado a partir de un proceso continuo de invasiones llamado recuperación de tierras.

${ }_{16}$ Viviendas consolidadas: son todos aquellos desarrollos de uso residencial que han alcanzado un nivel de construcción aceptable, utilizando dentro de sus materiales constructivos elementos como tejas de eternit, ladrillo y placas en concreto y pisos en baldosa generalmente común; pese a esto no se es posible afirmar que las condiciones de habitabilidad interna siempre sean las más adecuadas. Viviendas Semiconsolidadas: Son aquellas que se encuentran en un estado transitorio de consolidación, en donde los materiales usados no proveen de las condiciones necesarias para una adecuada habitabilidad o con marcado deterioro constructivo. Viviendas Sin consolidar: Son todos aquellos desarrollos de vivienda que presentan un alto grado de deterioro en sus materiales constructivos, generalmente son viviendas construidas con paredes en madera o materiales perecederos, techos en teja de zinc con pisos en tierra pisada o cemento rustico.
} 
situación ocurre debido a que dichas viviendas se han deteriorado por falta de mantenimiento (como consecuencia del bajo poder adquisitivo de sus pobladores) y han pasado de un estado aceptable a uno regular (semiconsolidado), lo que indica que las viviendas en mal estado (sin consolidar) no han mejorado su situación, sino que las consolidadas han perdido calidad.

Asimismo se aprecia un aumento significativo en las viviendas sin consolidar, develando la aparición de nuevos asentamientos informales en la periferia de la ciudad y en sectores contiguos a los bajos y cañadas que conectan con el humedal El Castillo.

Tabla 1 Total predios y comparación del estado de la vivienda en el periodo comprendido entre 2001 y 2007 en la Comuna 7

\begin{tabular}{lrrr}
\hline \multicolumn{1}{c}{ Estado de la vivienda } & $\mathbf{2 0 0 1}$ & $\mathbf{2 0 0 7}$ & Diferencia \\
Consolidada & 3.549 & 1.622 & -1.927 \\
Semiconsolidada & 172 & 1.915 & 1.743 \\
Sin Consolidar & 1.219 & 1.754 & 535 \\
Total Vivienda & 4.940 & 5.291 & 351 \\
Lotes & 468 & 392 & -76 \\
Predios destinados a otros & 67 & 93 & 26 \\
usos (comercio, industria) & & & \\
Total Predios & 5.475 & 5.776 & 301 \\
\hline aboración propia, con base en los datos de la Revisión y Ajuste Plan Parcial Comuna 7 (2007).
\end{tabular}

Finalmente en el tema de vivienda, existe otro aspecto relevante que destaca la presencia de 392 lotes al interior de los barrios, que cuentan con disponibilidad de redes de servicios públicos domiciliarios, aun cuando esto no significa que tengan buena calidad en la prestación del servicio. Con estos indicadores se puede inferir que el desarrollo progresivo de los barrios en la Comuna 7, en lugar de mejorar ha retrocedido y aún no se ha logrado avanzar en propuestas claras que permitan aminorar la urbanización informal evitando posteriores sobrecostos, tanto en la legalización de los asentamientos como en la dotación de infraestructura y equipamientos sociales básicos.

La segregación socio-espacial y políticas de planeación. La segregación espacial o residencial puede definirse como "...el grado de proximidad espacial o de aglomeración territorial de las familias pertenecientes a un mismo grupo social, sea que éste se defina en términos étnicos, etáreos, de preferencias religiosas o socioeconómicos, entre otras posibilidades" (Sabatini, Cáceres y Cerda, citado por Arriaga y Rodríguez, 2003:10). De otro lado, las políticas de planeación y de ordenación territorial urbana, han brillado por su ausencia en Barrancabermeja, aun cuando el Plan de Ordenamiento Territorial POT se encuentra aprobado, desde el año 2002, y pese a que dentro de sus estrategias centrales se plantea la disminución de los desequilibrios espaciales entre oriente y occidente. Es lamentable ver que las diferentes administraciones municipales han hecho caso omiso a las disposiciones del POT, situación que ha traído como consecuencia un aumento de las disparidades espaciales acrecentando la fragmentación de la ciudad y reforzando los estigmas hacia las comunas orientales (comunas 5,6 y 7), situación que le niega la posibilidad a sus comunidades de obtener una movilidad social ascendente y un mejor acceso servicios sociales básicos. En consecuencia la ciudad aun no avanza en la implementación de políticas públicas adecuadas que permitan equilibrar las brechas territoriales y funcionales en su interior, así como tampoco vislumbra propuestas sólidas entorno a la disminución de la exclusión social que la ha caracterizado desde sus inicios con la implantación de las multinacionales petroleras. 


\subsection{La propuesta de ordenación territorial participativa.}

Fundamentalmente la propuesta de ordenación comunal se planteó como objetivo central:

Formular un modelo de re-ordenamiento territorial a escala comunal que contribuya a mejorar las condiciones generales de la calidad de vida de los pobladores, guardando la aplicación de los principios de equidad social en el acceso a la prestación de los servicios sociales y públicos básicos, la sustentabilidad ambiental en las relaciones población-naturaleza y la productividad social y económica que permitan una vida digna para todos y todas (Plan Parcial Comuna 7, 2001).

Sus principales políticas de intervención se orientan dentro del marco general de la planeación participativa de sus comunidades, en la búsqueda de mejores y mayores niveles de bienestar social, político, económico y ambiental; para ello planteó 5 grandes políticas que son la base de las decisiones concertadas con la comunidad. La primera de las políticas, Equidad social en el acceso a servicios sociales y públicos básicos, busca garantizar que todas las poblaciones, no solo de la Comuna 7 sino del oriente de Barrancabermeja, puedan acceder a bienes y servicios públicos con prioridad y favorabilidad hacia los sectores pertenecientes a los estratos más bajos, para ello se plantea, entre otros, la adecuación y dotación de la infraestructura educativa comunal y el mejoramiento en la calidad y acceso a los servicios públicos domiciliarios.

La segunda política, Sustentabilidad ambiental, se inscribe "en el principio de la relación inteligente entre la población y la naturaleza, de manera que la interacción entre estos dos componentes vitales del territorio construyan un contrato de coexistencia que garantice la preservación del medio natural para las generaciones futuras" (Plan Parcial Comuna 7, 2001), para ello plantea que los elementos de dotación ambiental como el humedal el Castillo, bajos, quebradas y las áreas de espacio colectivo, se incorporen adecuadamente a la trama urbana propuesta, generando mayores índices de espacio público por habitante, y elevando la conciencia del valor ambiental de los ecosistemas presentes en la ciudad, haciendo especial énfasis en los de la Comuna 7.

La tercera, Productividad social y económica, pretende apartarse del sesgo economicista característico de los enfoques con los cuales se ha abordado el ordenamiento territorial en Colombia, considerando que es incuestionable que todos los procesos económicos en esencia son sociales, y resaltando que aunque muchos de ellos no produzcan grandes utilidades capitalizables económicamente, sí fortalecen el desarrollo de actividades productivas socialmente, en las cuales las comunidades obtienen satisfactores que aumentan su bienestar y calidad de vida.

La cuarta Infraestructura para el desarrollo social, es un aspecto central dentro de las necesidades más sentidas de la población, no solo por los equipamientos de salud y educación, sino por los relacionados con los servicios públicos domiciliarios, además se destaca su relevancia dentro de las políticas de desarrollo local y regional para la ciudad, ya que Barrancabermeja debe dotarse de una pertinente infraestructura en equipamientos colectivos que le permita insertarse, favorablemente y de manera competitiva con otras ciudades y regiones, en especial cuando ésta juega un papel geoestratégico, como nodo articulador, en el afianzamiento del canal seco entre el océano atlántico y el pacifico, desde el lago de Maracaibo Venezuela hasta el puerto de Tribuga en Colombia respectivamente.

La última, Desarrollo político e institucional, busca la descentralización funcional actual, mediante la creación de centralidades urbanas en el oriente de la ciudad, siendo un claro propósito la descentralización de las funciones político-administrativas desde el centro histórico hacia el oriente, de tal forma que se genere un desarrollo territorial más equilibrado y funcionalmente eficiente para la ciudad. El propósito de las centralidades no es otro que 
propiciar la construcción de nodos articuladores en el oriente de la ciudad, que permitan concentrar las actividades administrativas y económicas, con el fin de aumentar los niveles de funcionalidad e integración espacial urbana.

Adicionalmente a las políticas del plan parcial, el proyecto se construye socio-espacialmente alrededor de un lote de 150 hectáreas, cedido como pago parcial por el Ministerio de Defensa a la Alcaldía Municipal con el propósito de desarrollar el proyecto Ciudadela Educativa. Éste proyecto, liderado por el equipo gestor, es un acuerdo político comunitario de carácter integral (ver figura 2), en donde la construcción de un colegio de formación media vocacional no fue su único fin, sino que a su vez, permite la participación efectiva de las organizaciones sociales de base en el desarrollo de proyectos con productividad social y económica, en donde jóvenes, adultos, madres cabeza de familia, juntas de acción comunal (JAC), entre otras, adelantan actividades ambientalmente sostenibles en consonancia con la relación armónica entre medio ambiente y sociedad, constituyéndose en un ejemplo de organización y participación ciudadana para toda Barrancabermeja ${ }^{17}$.

Con lo expuesto anteriormente, se puede apreciar que la propuesta de ordenación comunal, no se limita solo a lo sectorial con una mirada exclusiva de lo inmediatamente físico-espacial, sino que trasciende los límites comunales urbanos, al tiempo que visualiza su accionar dentro del contexto regional del Magdalena Medio, propiciando que la Comuna 7, y el área urbana de Barrancabermeja, se conviertan en el centro nodal de integración funcional regional con perspectiva global, si se tiene presente que las vías contiguas a la ciudad y a la comuna serán el paso obligado para la interconexión del, ya mencionado, corredor seco entre Colombia y Venezuela.

Figura 2 Ejes estructurantes del Proyecto Ciudadela Educativa

\section{MODELO DE DESARROLLO INTEGRAL}

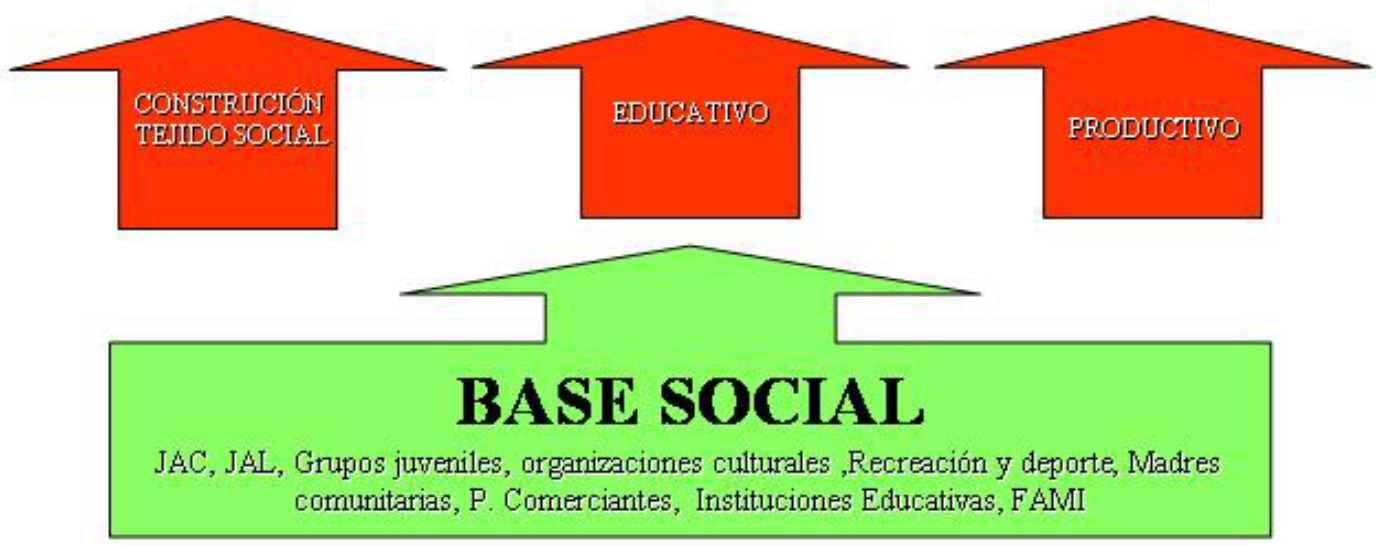

Fuente: Plan Parcial Comuna 7 (2001). JAC: Juntas de Acción Comunal. JAL: Juntas de Administradoras Locales. FAMI: Programa de Atención a la Familia la Mujer y el Infante.

\footnotetext{
${ }^{17}$ El proyecto Ciudadela Educativa y Desarrollo Integral de la Comuna 7 de Barrancabermeja, fue concebido por un grupo de ocho líderes comunitarios, que han construido una propuesta de planificación integral del desarrollo con perspectiva territorial, del cual surgió el ya mencionado documento Plan Parcial en el año 2001, y que en la actualidad avanza hacia la construcción de una propuesta para todo el oriente de la ciudad de Barrancabermeja.
} 


\section{Los retos y perspectivas futuras del proyecto}

Al llegar a este punto se observa que la propuesta participativa de ordenación territorial en la Comuna 7 de Barrancabermeja, trasciende los límites fijados inicialmente y se convierte en un ejercicio digno de replicar en otras ciudades del país, ya que su carácter incluyente y participativo, ha permitido que los líderes comunitarios hayan alcanzado un alto grado de autonomía (aun cuando no total) ante los grupos armados ilegales que han azotado la región, y que han sido causantes de las fuertes oleadas de desplazamiento forzado, de desapariciones y de implantación de miedo y el terror, como mecanismo para alcanzar el poder militar y territorial no solo a nivel local sino regional.

Un desafió inmediato del proceso, es lograr institucionalizar socialmente el proyecto en las otras comunas de Barrancabermeja, para ello, la propuesta de ordenación debe insertarse dentro de los temas a tratar en la revisión del Plan de Ordenamiento Territorial POT en el año 2008, garantizando definitivamente su permanencia y obligatorio cumplimiento en el tiempo. Otro de los retos, ligado estrechamente al anterior, es conseguir incidir verdaderamente en las políticas públicas, independientemente de la administración local de turno, ya que la falta de voluntad política hacia la implementación del proyecto, ha sido uno de los factores que dificultan la transformación del modelo actual (el cual se ha caracterizado por la exclusión territorial), y no permite pasar de la desarticulación y fragmentación territorial hacia un sistema funcional, articulado e incluyente social y espacialmente.

Por su parte el equipo gestor del proyecto Ciudadela Educativa, debe enfrentar el hecho de que necesita superar la particularidad comunal y generar alianzas con líderes de otras comunas, para construir un discurso alternativo, que direccione el proceso hacia un cambio histórico en la ciudad, en donde los sectores de origen informal se conviertan en espacios sociales constructores y reafirmantes de su verdadero poder político en la toma real de decisiones que involucran su propio desarrollo.

En cuanto a las perspectivas políticas futuras, se encuentra la posibilidad de que sus líderes amplíen sus fronteras, en busca de una dinámica urbana y regional, que les permita ocupar cargos públicos de incidencia en la formulación de directrices estratégicas para la ciudad y para el Magdalena Medio, ya que algunos de ellos se han insertado en procesos, como el adelantado desde hace varios años por el Sistema Regional de Planeación Participativa del Magdalena Medio SRPPMM, siendo este un ejemplo de planificación con perspectiva regional a nivel nacional, pese a los inconvenientes que dicho proceso ha experimentado.

\section{Reflexiones finales}

\subsection{De la ordenación del territorio}

Dentro del marco de ordenación del territorio comunal se debe exaltar que el proceso no fue liderado, como comúnmente sucede, por la administración municipal, sino que surge producto de la organización colectiva de las comunidades de base, en busca de una organización socioterritorial más incluyente y menos desequilibrada en sus funciones sociales básicas. De este proceso nace un acuerdo comunal entorno al re-ordenamiento de las transformaciones que históricamente los pobladores han efectuado sobre el medio natural, al tiempo que se avanza en la construcción de identidades frente a un interés colectivo, en la edificación de un proyecto socio-político de desarrollo local con perspectiva regional, donde la violencia, los desequilibrios espaciales, la fragmentación territorial y la segregación espacial negativa, no sean los aspectos centrales de distinción. 
En este mismo contexto, es interesante examinar que la sociedad civil, representada en los líderes de la Comuna 7 de Barrancabermeja, expresan su proyecto de desarrollo en una unidad socialmente construida alrededor de sus identidades culturales, históricas, sociales y políticas, legitimada por sus pobladores y con una expresión espacial real y concreta, al punto que trasciende los límites comunales actuales para promover un proceso mayor de ordenación territorial participativa en la ciudad y en la región.

\subsection{De los avances y retos del proyecto comunal}

A pesar de que el camino por recorrer es largo, el proyecto Ciudadela Educativa y Desarrollo Integral de la Comuna 7 de Barrancabermeja, con la realización participativa de su plan parcial, de su proyecto educativo comunal (PEC) y de su posterior plan de desarrollo, se constituye en referente regional y nacional de los procesos de planeación participativa con perspectiva territorial, e indiscutiblemente da claras evidencias de cómo las comunidades organizadas y fortalecidas, pese a la poca, o casi nula, voluntad política de las administraciones municipales locales, pueden gestionar recursos del orden nacional e internacional.

El ejercicio de planificación territorial comunal, liderado por el equipo gestor, y que ha contado en los últimos años con el acompañamiento del Programa de Desarrollo y Paz del Magdalena Medio, desde la formulación de su plan parcial, ha alcanzado una serie de resultados de tipo cualitativo y cuantitativo, reflejados principalmente en el aumento de la capacidad organizacional de sus comunidades, mayor fuerza y respaldo social en la resistencia civil hacia los grupos en conflicto armado ${ }^{18}$ e incidencia directa en la formulación de su propio Proyecto Educativo Comunal (PEC), entre otras.

Desde el punto de vista cuantitativo, el proyecto ha conseguido autonomía en la toma de decisiones sobre el uso del suelo del predio de 150 hectáreas, antigua propiedad de las fuerzas armadas, en donde actualmente las diferentes organizaciones de base con asiento en la comuna, llevan a cabo proyectos ambientales y de productividad social y económica, alcanzando grandes logros como la disminución del robo de gasolina de los poliductos que pasan contiguos al predio.

Finalmente, cabe concluir que pese a la falta de voluntad política de las diferentes administraciones municipales, el proyecto Ciudadela Educativa es la representación más clara y exitosa de la sociedad civil del Magdalena Medio como agente promotor de desarrollo social, político, ambiental y de organización espacial en barrios de origen informal.

\footnotetext{
${ }^{18}$ A lo largo de los últimos 10 años la Comuna 7 ha vivido en distintas épocas el enfrentamiento entre guerrillas (ELN, FARC) y paramilitares, $y$, hasta hace menos de dos años el enfrentamiento por el robo de gasolina.
} 
Bibliografía

Archila, M., Bolívar, I., Delgado, A., García, M., González, F., Madariaga, P., Prada, E. y Vásquez, T. Conflictos, poderes e identidades en el Magdalena Medio 1990-2001. Bogotá: Antropos, 2006.

Deininger, Klaus. Land Policies for Growth and Poverty Reduction (Niño Torres, Teresa, Trad.). Bogotá: Alfaomega, 2004.

Vargas, Alejo. Notas sobre El estado y las políticas públicas. Bogotá: Almudena, 2001.

Artículos de revistas

Arriagada, C. y Rodríguez, J. Segregación residencial en áreas metropolitanas de América Latina. Serie población y desarrollo, 2003. Santiago de Chile: Centro Latinoamericano y Caribeño de Demografía CELADE.

Sabatini, Francisco. La segregación social del espacio en las ciudades de América Latina. Documentos del Instituto de Estudios Urbanos de la Universidad de Chile, 2003, Serie Azul No 35.

Documentos técnicos consultados

Convenio Equipo Gestor Ciudadela Educativa, Ecopetrol, Alcaldía de Barrancabermeja, interconexión Eléctrica S.A. ISA. Programa de Desarrollo y Paz del Magdalena Medio. Plan Parcial y Unidad de Gestión Urbanística Ciudadela Educativa. Barrancabermeja, 2001.

Corporación Ciudadela Educativa y Desarrollo Integral de la Comuna 7. Revisión y Ajuste Plan Parcial Comuna 7 de Barrancabermeja. Barrancabermeja, 2007.

Corporación Desarrollo y Paz del Magdalena Medio. Plan de Desarrollo Comuna 7 de Barrancabermeja. Barrancabermeja, 2004. 